\title{
院内媻绪リン酸クリンダマイシンローションの安定性
}

\author{
廣田育彦，大植謙一，芳賀 泉，中島繁美 \\ 関西医科大学附属病院薬郕部*
}

\section{Stability of Clindamycin Phosphate Lotion Prepared in Hospital Pharmacy}

\author{
YASUHIKo HIROTA, KENICHI OHUE, IZUMI HAGA and SIGEMI NAKAZIMA \\ Department of Hospital Pharmacy, Kansai Medical University*
}

(Received July 19, 1985)

Topical clindamycin is used in the treatment of acne vulgaris at this time. In hospital pharmacy, $1 \%$ clindamycin phosphate lotion for acne vulgaris is prepared from the injectable form of clindamycin phosphate dissolved in the hydroalcoholic vehicle.

Stability of the preparation and $1 \%$ clindamycin phosphate aqueous solution was studied at $5^{\circ}$ and $25^{\circ}$ for 180 day. The $\mathrm{pH}$ of the sample was observed along with a periodical visual inspection. The amount of clindamycin phosphate in solution was determined by reversed-phase ion-pairing high-performance liquid chromatography (HPLC) with UV detector at $210 \mathrm{~nm}$.

$1 \%$ clindamycin phosphate lotion maintained $92 \%$ of its activity during the period of 180 days at $5^{\circ}$, and $88 \%$ at $25^{\circ} .1 \%$ clindamycin phosphate aqueous solution retained $91 \%$ of its activity over the period of 180 days at $5^{\circ}$, and $90 \%$ at $25^{\circ}$. As a primary degradation product of clindamycin phosphate in solution, lincomycin-2-phosphate was found in small amount.

$1 \%$ clindamycin phosphate lotion is relatively stable and good for more than 180 days at $5^{\circ}$.

Keywords - $1 \%$ clindamycin phosphate lotion; stability; temperature; degradation product of clindamycin phosphate; activity; topical clindamycin

\section{はじめに}

平常痤癌の治療において, 抗生物質の内服療法はその 有効性が認められ，一般に広く用いられている.1,2)しか し, 抗生物質の経口投与には副作用の問題があり, 局所 療法による治療が試みられている.3 6)

抗生物質を局所に適用すること火より，開放面皮内の Propionibacterium acnes の菌数が減少し, 同時に炎症 に重要な関わりを持つと考えられている遊離脂肪酸も減 少し, その結果として带常痤癌の病像が好転することが 知られている.3,4,7)

クリンダマイシンは in vitro で Propionibacterium acnes に対して抗菌活性を有しており，雭常痤瘄に対し て局所療法による治療効果が期待されている. ${ }^{3,4,6)}$

* 守口市文園町 1 ； 1, Humizono-cho, Moriguchi-shi, Osaka, 570 Japan
当院では皮膚科の依頼により，琶常痤痽に対する局所 療法剂として，1\%リン酸クリンダマイシンローション を院内製剤している. 本製剂の主成分は Clindamycin2-phosphate であり, 半合成抗生物質クリンダマイシン のリン酸エステルである (Fig. 1). リン酸クリンダマ イシンは生体内で速やかに加水分解され, クリンダマイ シンとして抗菌作用を示す.

今回, 本製剤及び $1 \%$ ン酸クリンダマイシン水溶液 の外観変化, $\mathrm{pH}$ の変化, リン酸クリンダマイシンの残 存力価を調製時から 180 日間経時的に観察し, その安定 性を検討した。また，リン酸クリンダマイシンの分解物 の 1 つを同定した.

实臨 の 部

\section{1. 试 落}

Clindamycin-2-phosphate 敒び Lincomycin-2-phosphate の標準試薬は日本アップショョン社より提供され 


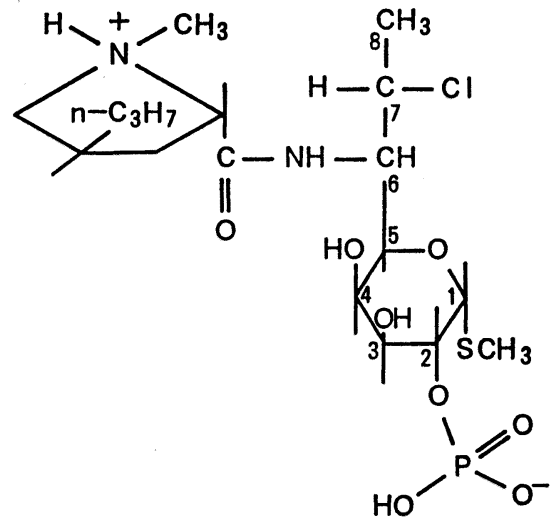

(I)

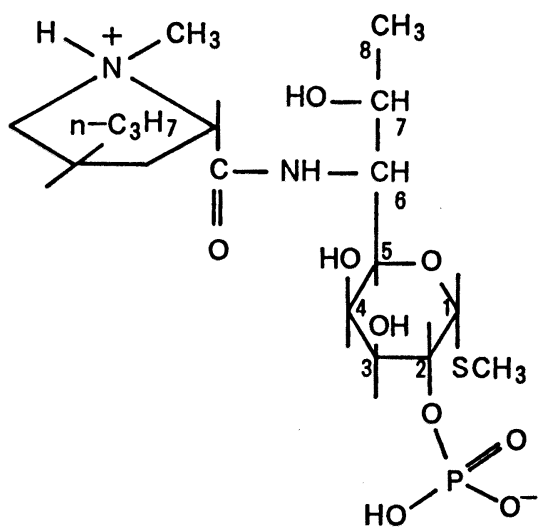

(II)

Fig. 1. Structural Formulae of Clindamycin-2-Phosphate (I) \& Lincomycin-2Phosphate (II)

たものを用いた。

\section{2. 試料の濑及び保存条件}

リン酸クリンダマイシンローションの処方を Table 1 飞示す. ${ }^{4 \sim 6,8,9)}$ 注射用リン酸クリンダマイシン(日本アッ プジョン社, Lot No. LH 101) を用いて, リン酸クリン ダマイシンローション及びリン酸クリンダマイシン水溶 液を調製し, 容量 $2 \mathrm{ml}$ のガラス製サンプル瓶に約 $1 \mathrm{ml}$ ず つ, 容量 $50 \mathrm{ml}$ のマイヤーフラスコに約 $30 \mathrm{ml}$ ずつ分注 乙, 密柽を施した後, $5^{\circ}\left( \pm 2^{\circ}\right)$ と $2^{\circ}\left( \pm 2^{\circ}\right)$ で遮光 保存した.ガラス製サンプル瓶入りの試料は残存力価の 測定に用い, マイヤーフラスコ入りのものは外観変化の 観察及び $\mathrm{pH}$ 測定の試料に供した.

\section{3. 外㩓变化}

マイヤーフラスコ入りの試料を $\mathrm{pH}$ 測定前に室内散光 下で外観の変化を観察した。

\section{4. pH 测定}

日立・堀場 F-7DE 型 $\mathrm{pH}$ メーターを用いて測定し た。

\section{5. リン砵クリンダマイシン残存力価の测定}

リン酸クリンダマイシンの残存力価は逆相イオン・ペ

Table 1. Clindamycin Phosphate Lotion Formulation

\section{Clindamycin Phosphate} for Injection $\quad 600 \mathrm{mg}$

70\% Isopropanol

$48 \mathrm{ml}$

Propylene Glycol

$6 \mathrm{ml}$

Distilled Water

q.s.

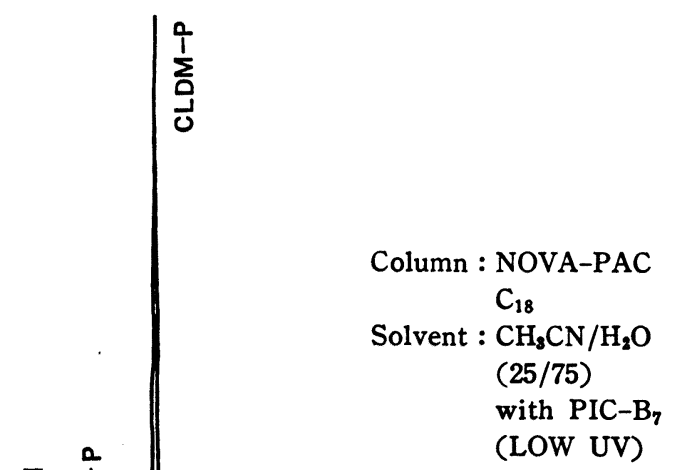

Flow Rate $: 2.0 \mathrm{ml} / \mathrm{min}$ Detector : UV $210 \mathrm{~nm}$
Total

$60 \mathrm{ml}$

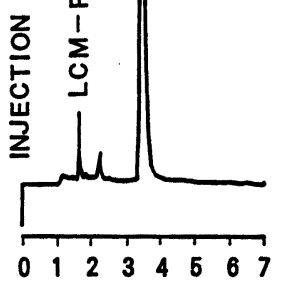

RETENTION TIME (min)

Fig. 2. HPLC Chromatogram of Lincomycin2-Phosphate(LCM-P) and Clindamycin2-Phosphate (CLDM-P) in Solution

アークロマトグラフィー (HPLC) により測定した。 ${ }^{10,111}$ ポンプは 510 型（ウォーターズ社），インジェクターは U6K型 (ウォーターズ社), カラムはラジフルパックカ ートリッジ・NOVA-PAK C 18 (ウォーターズ社), 移動 相はアセトニトリル：水 (25: 75) とカウンターイォン として PIC-B . LOW UV（ウォーターズ社）を加えた すのを使用した。流速は毎分 $2.0 \mathrm{ml}$, 検出器はラムダ・ マックス 481 型（ウォーターズ社）を用い，検出波長は 
$210 \mathrm{~nm}$ とした. インテグレーターは島津・CHROMATOPAC C-RIB を用い,ピーク面積に基づいて絶対検 量線法により定量した（Fig. 2).

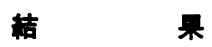

\section{1. 外}

リン酸クリンダマイシンローション及びリン酸クリン ダマイシン水溶液の外観は $5^{\circ}$ と $25^{\circ}$ 保存ともに 180 日後 までは著明な変化が認められなかった。

2. $\mathbf{p H}$

$\mathrm{pH}$ の測定結果を Table 2 に示す. いずれも特に変化 は認められなかった。

3. リン䚙クリンダマイシンの残存力価

リン酸クリンダマイシンローションのクリンダマイシ
ン残存率の経時変化を Fig. 3 に示す. $5^{\circ}$ 保存では180 日後の残存率は92\%であった．これに対し，250 保存で は150日後までは90\%以上の残存率が認められたが, 180 日後には $88 \%$ となった。

リン酸クリンダマイシン水溶液のクリンダマイシン残 存率の経時変化を Fig. 4 に示す. 180 日後の残存率は $5 \circ$ 保存で91\%，250 保存では90\%が認められた。

\section{4. リン酸クリンダマイシンの分解物の同定}

HPLC クロマトグラムにおいて，保存時間1.6分付近 に現れるピークが各試料の保存温度によってその面積に 差が認められた (Fig. 2). すなわち，このピークの面 積を Clindamycin-2-phosphate のピーク面積に対する 百分率で表わすと, リン酸クリンダマイシンローション の場合，180 日後で $5 \circ$ 保存では $2.2 \%$ であるのに対し

Table 2. Changes in $\mathrm{pH}$ Value of Clindamycin Phosphate Lotion \& Clindamycin Phosphate Aqueous Solution

\begin{tabular}{|l|c|c|c|c|c|c|c|c|c|c|c|}
\hline \multicolumn{2}{|c|}{} & - & $7 \mathrm{D}$ & $14 \mathrm{D}$ & $21 \mathrm{D}$ & $28 \mathrm{D}$ & $60 \mathrm{D}$ & $90 \mathrm{D}$ & $120 \mathrm{D}$ & $150 \mathrm{D}$ & $180 \mathrm{D}$ \\
\hline \multirow{2}{*}{$\begin{array}{l}\text { LLDM-P } \\
\text { LOTION }\end{array}$} & $25^{\circ} \mathrm{C}$ & 6.88 & 6.88 & 6.90 & 6.97 & 6.92 & 7.01 & 6.95 & 6.97 & 6.97 & 6.97 \\
\cline { 2 - 11 } & $5^{\circ} \mathrm{C}$ & 6.88 & 6.90 & 6.81 & 6.98 & 6.94 & 7.03 & 6.98 & 6.99 & 6.99 & 6.98 \\
\hline $\begin{array}{l}\text { CLDM-P } \\
\text { AO. SOLN. }\end{array}$ & $25^{\circ} \mathrm{C}$ & 6.58 & 6.55 & 6.59 & 6.51 & 6.50 & 6.53 & 6.49 & 6.50 & 6.50 & 6.49 \\
\cline { 2 - 11 } & $5^{\circ} \mathrm{C}$ & 6.58 & 6.56 & 6.58 & 6.53 & 6.53 & 6.56 & 6.54 & 6.53 & 6.52 & 6.52 \\
\hline
\end{tabular}

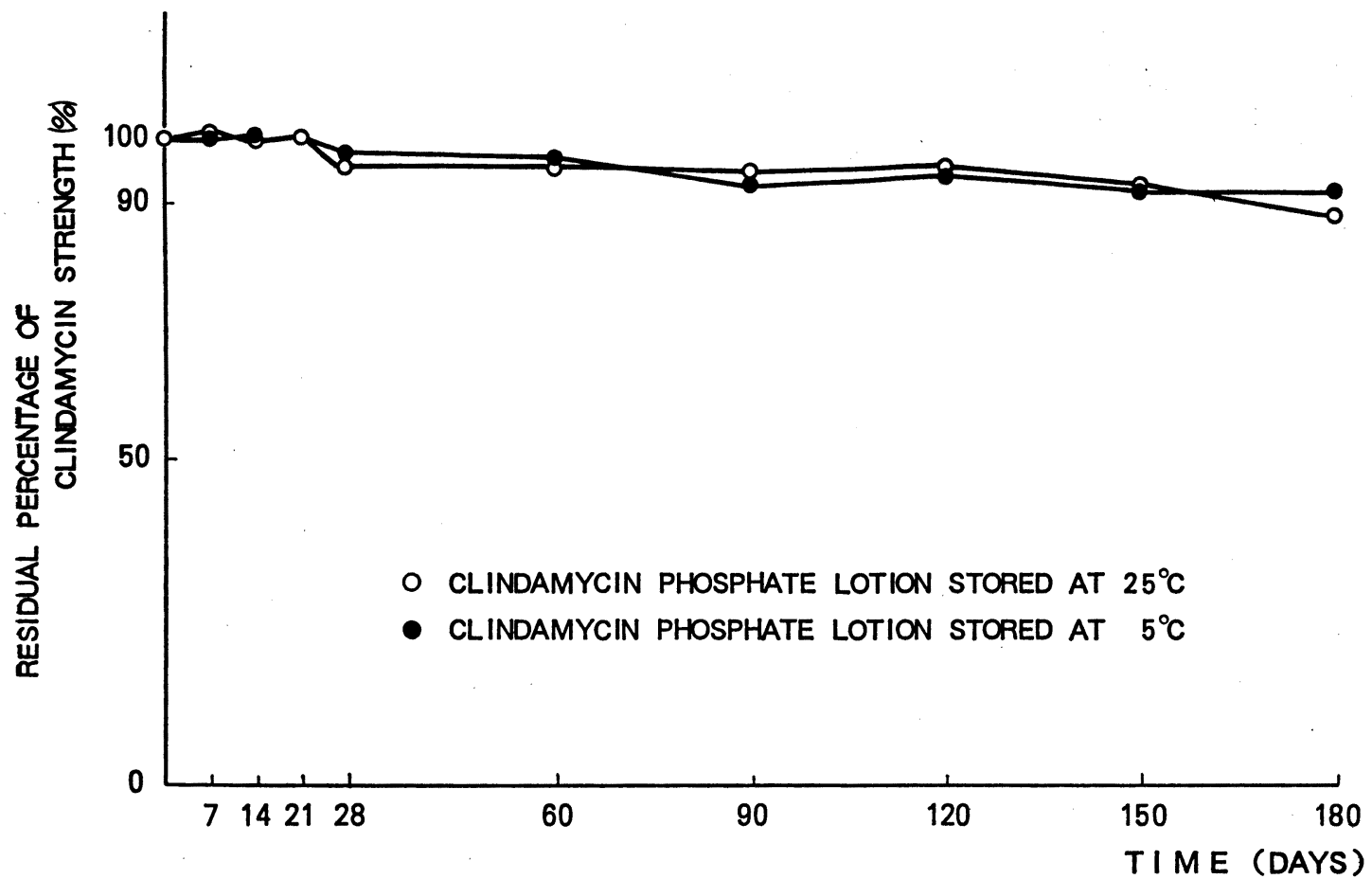

Fig. 3. Changes in Clindamycin Strength of Clindamycin Phosphate Lotion 


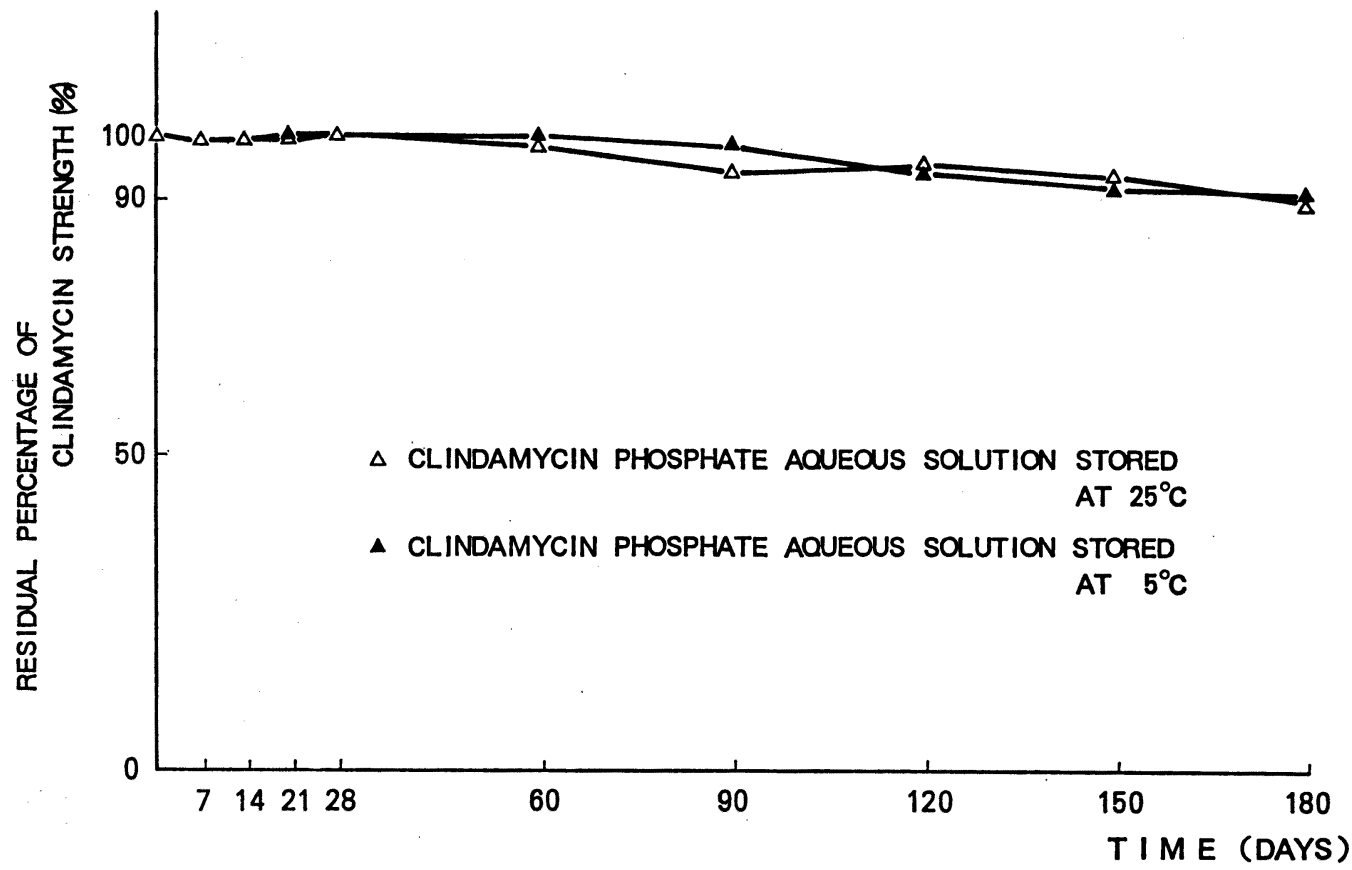

Fig. 4. Changes in Clindamycin Strength of Clindamycin Phosphate Aqueous Solution

て, 25保存では3.6\%が認められた。また,リン酸クリ ンダマイシン水溶液では, 180 日後, 5保存て $2.5 \%, 25^{\circ}$ 保存では $4.2 \%$ が認められた。このように, 保存温度の 上㫒とともにピーク面積が増大しているため,このピー クは Clindamycin-2-phosphate の分解物の1 つと考え られた.この分解物は Lincomycin-2-phosphate の標準 品の保持時間と一致したことにより, Lincomycin-2phosphate と同定した。

\section{考实}

Lincomycin-2-phosphate $は$ Clindamycin-2-phosphate の $7(\mathrm{~S})-\mathrm{Cl}$ が分解を受け， $7(\mathrm{R})-\mathrm{OH}$ となった ものである (Fig. 1).

Oesterling12) の報告によると, クリンダマイシンは $\mathrm{pH}$ が 5 〜 10の水溶液では, 主たる分解過程は 7(S)-C1 が分解され， $7(\mathrm{R})-\mathrm{OH}$ に転換されてリンュマイシンと なる経路であるとされている.さらに，この過程は中間 体として oxazolonium を経由して進行し，この反応が クリンダマイシンのアミンの protonation の程度に依存 するるのと仮定されている.

Oesterling $5^{13)} は$, Clindamycin-2-phosphate につ いて, pH が6以下の場合には, リン酸エステル及びチ オグリコシドの加水分解, $\mathrm{pH} 6$ 以上では $7(\mathrm{~S})-\mathrm{Cl}$ が
分解を受け， $7(\mathrm{R})-\mathrm{OH}$ に転換される反応が主な分解 過程であると報告している. $\mathrm{pH}$ が 6 以上の場合には， Clindamycin-2-phosphate のリン酸エステル部分は比 較的安定であり, Lincomycin-2-phosphate への転換が 主要な分解経路である。

院内製放リン酸クリンダマイシンローションは, pH 值の大きな变動が認められず, 50 保存では少なくとる

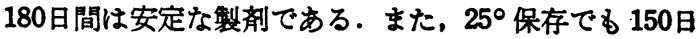
間は安定な製剤といえる。

賠辞 本研究にあたり貫重な標準品を提供していたた いた日本フッブション株式会社に深謝致します。

\section{文}

1) D.K. Chalker and J.G. Smith, Jr. : JAMA, 234, 1058 (1975).

2) E.T. Poulos and F.J. Tedesco : Arch. Dermatol., 112, 974 (1976).

3) W. Resh and R.B.Stoughton : Arch.Dermatol., 112, 182 (1976).

4) R.B. Stoughton and W. Resh : Cutis, 17, 551 (1976).

5) R. B. Stoughton : Arch. Dermatol., 115, 486 (1979).

6) R.S.Padilla, J.M. McCabe and L.E. Becker : Int. J. Dermatol., 20, 445 (1981). 
7) W.J.Cunliffe, J.A.Cotterill and B.Williamson : Br.J.Derm., 87, 37 (1972).

8) N.C.Lacina, R.J. Orr, L.S. Peters and G. L. Flynn: Am.Pharm.NS, 18, 614 (1978).

9) R.J.Orr, N.C.Lacina, L.S. Peters and G. L. Flynn: Am.Pharm.NS, 18, 663 (1978).
10) J.B.Landis, M.E.Grant and S.A. Nelson : J. Chromatogr., 202, 99 (1980).

11) L.W. Brown : J.Pharm. Sci., 67, 1254 (1978).

12) T.O.Oestering: J.Pharm.Sci., 59, 63 (1970).

13) T.O. Oesterling and E.L. Rowe: J. Pharm. Sci., 59, 175 (1970).

\section{劇 胆汁分泌促進剤}

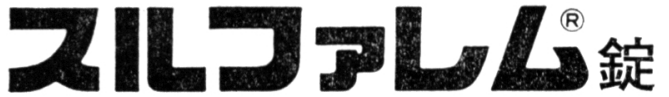

アネトールトリチオン $12.5 \mathrm{mg} /$ 錠 含有

〔適 広 症〕下記疾患における利胆

胆道（胆管・胆のう）系疾患及び胆 汁うっ滞を伴う幷疾患

〔用法用量〕アネトールトリチオンとして通常成 人 1 回 $25 \mathrm{mg}$ ⿸ 1 日 3 回経口投与 年令・症状に上り適宜増減

〔薬理作用〕 (1) 催胆作用

(2) 旰機能賦活作用（血中 G S H 值上: 昇/色素排泄能促進/尿素合成能 促進 / 肺コレステロール量調整)

薬理作用の詳縕及び使用上の注意については製品 添付文書をご参照下さい。

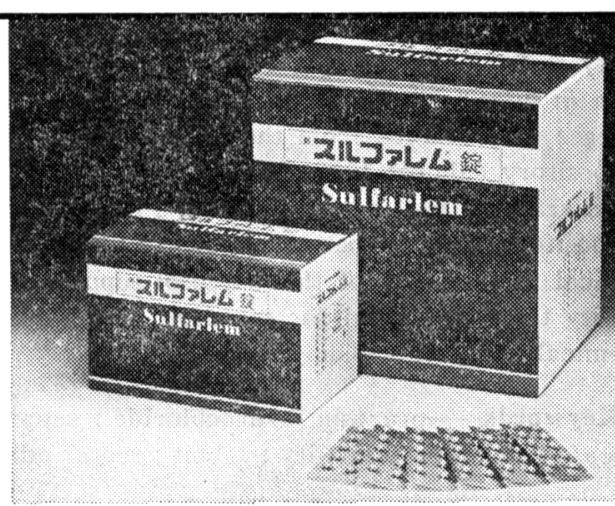

〔包装〕

1,200 錠 6,000 錠

(PTP） 10錠 $\times 12010$ 錠 $\times 600$

○同一成分製剂にスルファレム丸 $(12.5 \mathrm{mg} /$ 丸)があります。 規制区分：劇 薬

薬価基準収載品

製造東菱薬品工業株式会社 東京都千代田区有楽町1-10-1

提携 ラ テ マ 社(フランス) 販壳元 挂桑薬昆工業株式会社 大服市東区道修町 2 丁目 50 番地 